\title{
Variation in assimilating functions occurs in spontaneous Candida albicans mutants having chromosomal alterations
}

\author{
E. P. Rustchenko, ' D. H. Howard' ${ }^{2}$ and F. Sherman' \\ Author for correspondence: Elena P. Rustchenko. Tel: +1716 275 6710. Fax: +1 7162712683. \\ e-mail: bulgac@mail.medinfo.rochester.edu
}

1 Department of
Biochemistry and
Biophysics, University of
Rochester School of
Medicine and Dentistry,
Rochester, NY 14642, USA
2 Department of
Microbiology and
Immunology, UCLA School
of Medicine, University of
California, Los Angeles, CA
90024, USA

\begin{abstract}
In this study, four clinical isolates and over 100 colony morphology mutants, previously derived spontaneously from strain 3153A during growth on glucose medium, were examined for their utilization of 21 carbon and 3 nitrogen sources at various growth temperatures. The results demonstrated extensive variability in the pattern of assimilation among the mutants and strains, including both the gain and loss of assimilating functions. The persistent alterations in assimilation patterns observed in sequentially produced subclones illustrated an extensive ability of $C$. albicans populations to constantly produce new combinations of assimilating functions. The variability among spontaneous mutants derived from a single strain explains the well documented variability among natural isolates. From these results we established a relationship between the previously documented broad spectrum of spontaneous chromosomal aberrations in these mutants to the expression of genes controlling the utilization of alternative carbon and nitrogen sources. The existence of cryptic genes, responsible for growth on alternative substrates, was previously deduced from the analysis of other mutants obtained as a response to the restrictive condition on media containing non-assimilating carbon sources. Thus, mutants with altered assimilation functions can arise either on glucose medium or by selection on restricted media. Extensive differences between the patterns of chromosomal aberrations and the distribution of correlated phenotypes in the two groups of mutants indicated that the same phenotypes may be produced by two different mechanisms involving the same or different genes.
\end{abstract}

Keywords: Candida albicans, carbon assimilation, nitrogen assimilation, genetic instability, chromosomal aberrations

\section{INTRODUCTION}

The spontaneous occurrence of different colony forms of Candida albicans was first reported 60 years ago (Negroni, 1935) and has been extensively studied by numerous investigators (for a review, see Odds, 1988). After the initial discovery, the variability of colony form was related to the variability of many other phenotypes, including traits used for taxonomic assignment, such as germination or carbon assimilation (Brown-Thomsen, 1968; Howard et al., 1986; Rustchenko-Bulgac \& Howard, 1993), traits believed to be correlated with putative pathogenic factors such as, for example, adhesion (Vasilas et al., 1992) and colonization (Meitner et al., 1990), as well as virulence for laboratory animals (Mackinnon, 1940; Vogel \& Sponcler, 1970). Despite a substantial amount of data on phenotypic variability related to the altered colonies, its significance has, until now, remained unclear.

Using PFGE, we established a correlation between colony morphologies and spontaneous chromosomal aberrations (Rustchenko-Bulgac et al., 1990; Rustchenko-Bulgac, 1991). This conclusion is supported not only by studies with C. albicans strain 3153A, but also with strains NUM961 (Suzuki et al., 1989), 307 and 310 (Rustchenko-Bulgac \& Howard, 1993), and ATCC 32077 (M. J. McEachern, University of San Francisco, CA, unpuiclished results), as well as with Candida tropicalis pK233 (Suzuki et al., 1991). Thus, the occurrence of chromosomal aberrations in morphological mutants may be a general phenomenon found in many, 
if not all, strains of C. albicans and related species, consistent with the numerous early reports of altered colony forms. Although colony morphology is not an essential trait for C. albicans, it nevertheless provides an easy and convenient means to identify clones with altered chromosomes.

In the context of this paper, we have used the term 'mutation' as an inheritable change, without implying any specific molecular mechanisms.

The phenomenon termed 'high-frequency switching of colony morphologies', was claimed by Slutsky et al. (1985) to describe the mutual interconversion of seven morphological forms. As emphasized by Soll (1990), '... in the Candida switching system, reversibility is a major factor...' However, we have not observed the reversibility accentuated by Soll (1990), although there is a high degree of variability in colony morphology (Rustchenko-Bulgac, 1991). In fact, we believe Soll and his coworkers described the same phenomenon that was previously investigated by many other workers (Odds, 1988), and later by us. The lack of reversibility was also noted by others, including Pomés et al. (1985). In addition, Slutsky et al. (1985) emphasized in their original paper the lack of true reversion to the parental type. Thus, we have chosen not to use the term 'switch' even though the phenomenon we observed bears a close resemblance to the one described by Soll (1990).

Furthermore, a second 'high-frequency switching system', the white-opaque transition reported to occur in strain WO-1 (Slutsky et al., 1987), is clearly distinct from the spontaneous mutants described herein. In contrast to the mutants that are the subject of this paper, the mutants arising by white-opaque transition can occur by mass conversion, and do not have altered electrophoretic karyotypes (Rikkerink et al., 1988).

We suggested that frequent spontaneous aberrations are the means to achieve genetic variability in an organism that lacks a sexual process (Rustchenko-Bulgac et al., 1990). In a systematic effort to elucidate the relationship between chromosomal aberrations and advantageous phenotypes, we have employed a collection of spontaneous mutants with altered electrophoretic karyotypes, the so-called morphological mutants (Rustchenko-Bulgac, 1991), which were detected on the basis of their altered colony morphologies. Although many phenotypes were found initially to be affected in these mutants, these traits, such as altered colony or cell morphology, did not appear to be advantageous for the organism. Also, other alterations appeared to be the results of diminished or destroyed functions, such as the inability to form germ tubes or chlamydospores (Rustchenko-Bulgac \& Howard, 1993), as well as diminution of adherence (C. Haidaris, University of Rochester, NY, unpublished results) and virulence (E. DiDomenico, Schering Plough Research, Bloomfield, NJ, unpublished results), appearing in some, but not all mutants.

In this paper we report for the first time that each spontaneously derived morphological mutant possesses a unique assimilation profile for carbon or nitrogen sources. Changes in assimilation profiles include both loss and acquisition of functions, which suggests the existence of cryptic genes. The comparison between morphological mutants, which occurred spontaneously during growth on glucose, and previously reported mutants which were produced under restrictive conditions in an obvious response to the replacement of glucose by non-assimilative carbon sources (Rustchenko et al., 1994), revealed profound differences. The differences in the patterns of chromosomal rearrangements and the differences in the distribution of associated phenotypes indicated that the two groups of mutants may have arisen by two different mechanisms involving either the same or different genes.

A complex control of the ability to change the capacity to assimilate a wide range of nutrients is a general feature shared by all or most microbes, although the mechanisms responsible for the variations can differ significantly. C. albicans appears to have evolved an unusual means to produce a high level of variation to cope with the changing nutritional environment of the host.

\section{METHODS}

Strains of $C$. albicans. The origins of the four clinical isolates $3153 \mathrm{~A}, \mathrm{C} 9, \mathrm{FC} 18$ and WO-1, which are widely used laboratory strains, have been described previously (Rustchenko-Bulgac, 1991). All other strains used herein were derived from 3153A by two means. 'Colony morphology mutants' or 'morphological mutants' arose during the growth of 3153A on glucose and were subsequently detected on LBC medium (Lee $e t$ al., 1975) by the altered appearances of their colonies (Rustchenko-Bulgac et al., 1990; Rustchenko-Bulgac, 1991). In contrast, Sor1-Sor10, and Ara1, Ara2, Ara4 and Ara5 mutants arose after plating $3153 \mathrm{~A}$ cells on alternate non-assimilative carbon sources, L-sorbose and D-arabinose, respectively, in response to the restrictive condition (Rustchenko et al., 1994). The origins and interrelationships between the following morphological mutants have been described previously and are presented in Fig. 1: $\mathrm{m} 1-\mathrm{m} 20$ and $\mathrm{m} 500$ were derived directly from 3153A during growth on glucose medium and were detected on LBC medium (Lee et al., 1975) by the altered appearance of their colonies (Rustchenko-Bulgac et al., 1990; Rustchenko-Bulgac, 1991); descendants derived spontaneously from $\mathrm{m} 14$ and $\mathrm{m} 500$ by multiple rounds of subcloning (Rustchenko-Bulgac, 1991); strain 300, an unstable variant of 3153A (Rustchenko-Bulgac \& Howard, 1993); and spontaneous mutants 301, 302, 303 and 300-SG derived from 300, originally detected because of their inability to germinate (further studies revealed that they could also be considered morphological mutants; Rustchenko-Bulgac \& Howard, 1993). The 106 morphological mutants used in this study are also listed in Table 5 .

Maintenance and growth of strains. Because of the instability of C. albicans strains, a special method of maintenance at $-70^{\circ} \mathrm{C}$ and growth of strains, which avoids subcloning, was used in these studies (Rustchenko-Bulgac, 1991; RustchenkoBulgac \& Howard, 1993). The recipes for Yeast Extract Peptone Dextrose (YPD) medium, Glucose Peptone Agar (GPA) and Lee-Buckley-Campbell (LBC) synthetic medium have been published (Howard et al., 1986; Sherman et al., 
1986; Lee et al., 1975). Utilization of carbon sources was tested with Bacto Yeast Nitrogen Base without amino acids (YNB; Difco) and utilization of nitrogen sources was tested with Bacto Yeast Carbon Base (YCB; Difco).

Assimilation and physiological studies. The utilization of carbon sources (Table 1) was tested on media with $2 \%(\mathrm{w} / \mathrm{v})$ additions to YNB containing $2 \%(\mathrm{w} / \mathrm{v})$ agar. Similarly, utilization of nitrogen sources (Table 1) was tested on media with $2 \%(\mathrm{w} / \mathrm{v})$ additions to $\mathrm{YCB}$ containing $2 \%(\mathrm{w} / \mathrm{v})$ glucose and $2 \%$ agar. Freshly grown cells from plates were suspended in sterile water and small droplets of the cell suspensions were conveniently transferred to the various plates with replicating rods, as previously described (Sherman et al., 1986). Triplicate plates of each medium were incubated at 22,37 and $40^{\circ} \mathrm{C}$, respectively, for a period of 2 weeks. In addition, growth at $30^{\circ} \mathrm{C}$ was determined, but these data are not presented. To ensure exact and stable temperatures of 37 and $40^{\circ} \mathrm{C}$, plates were placed in plastic containers and incubated in water baths. The relative levels of growth and the appearance of papillae were recorded daily for the first $3 \mathrm{~d}$, and then weekly for 2 weeks. Tolerance to $\mathrm{pH} 1 \cdot 55$, tolerance to salt, and utilization of urea and sorbose were tested in the manner described by Odds \& Abbott (1980).

\section{RESULTS}

\section{Strains used in this study}

As presented in Fig. 1, we have analysed the four common laboratory strains (former clinical isolates) 3153A, C9, FC18 and WO-1, whose electrophoretic karyotypes were investigated previously (RustchenkoBulgac, 1991; Rustchenko-Bulgac et al., 1990; Rustchenko-Bulgac \& Howard, 1993). The remaining strains, all derived from 3153A are described in Methods and their interrelationships are summarized in Fig. 1. The electrophoretic karyotypes of 46 of the 106 spontaneous morphological mutants were characterized previously and each mutant was found to be uniquely altered (Rustchenko-Bulgac et al., 1990; RustchenkoBulgac, 1991; Rustchenko-Bulgac \& Howard, 1993). Some of these mutants represent a series of sequentially derived subclones having continually variable electrophoretic karyotypes and morphological phenotypes (Rustchenko-Bulgac, 1991). The electrophoretic karyotypes were also determined in the mutants Sor1-Sor10, and Ara1, Ara2, Ara4 and Ara5 obtained on restrictive media (see Methods). Unlike the spontaneous morphological mutants, the mutants obtained on restrictive media had identical patterns of chromosomal alterations specific for each phenotype. As described below, the mutants obtained on restrictive media were compared to the morphological mutants.

\section{Utilization of carbon and nitrogen sources by spontaneous morphological mutants of $\boldsymbol{C}$. albicans}

All of the mutants described above were tested for growth on media with the 21 carbon sources and 3 nitrogen sources listed in Table 1 . The assimilation tests at incubation temperatures of 22 and $30^{\circ} \mathrm{C}$ were repeated at least four times, and overall the results were highly reproducible. The data obtained at $30^{\circ} \mathrm{C}$ are not presented here for the sake of brevity. In addition, each

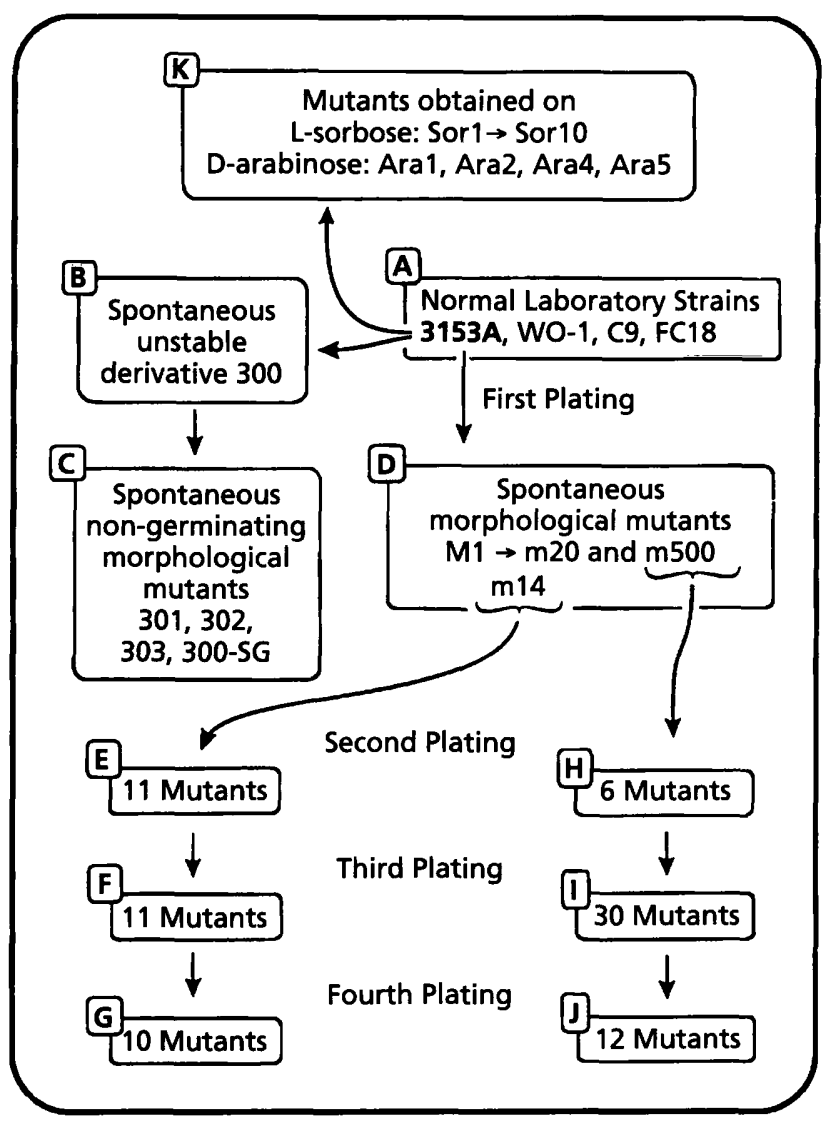

Fig. 1. Origin and interrelationships of $C$. albicans strains. Group A, normal laboratory strains; Group B, a spontaneous unstable derivative (300); Group $C$, non-germinating morphological mutants spontaneously derived from strain 300 ; Group D, spontaneously derived morphological mutants, including the highly unstable mutants $\mathrm{m} 14$ and $\mathrm{m} 500$; Groups $E, F$ and $G$, spontaneous mutants derived by sequential rounds of subcloning of $\mathrm{m} 14$; Groups $\mathrm{H}, \mathrm{I}$ and J, spontaneous mutants derived by sequential rounds of subcloning of $\mathrm{m} 500$; Group $K$, positive mutants produced as a response to alternative carbon sources, L-sorbose and D-arabinose. The strains are individually listed in Table 5. The electrophoretic karyotypes and various phenotypes of the normal strains and numerous mutants have been described previously (Rustchenko-Bulgac et al., 1990; Rustchenko-Bulgac, 1991; Rustchenko-Bulgac \& Howard, 1993).

of the assimilation tests was performed at incubation temperatures of 37 and $40^{\circ} \mathrm{C}$, which allowed comparison with our previous results with mutants produced by plating the parental strain $3153 \mathrm{~A}$ on non-assimilating carbon sources. We wish to point out that the results at 30 and $37^{\circ} \mathrm{C}$ were identical for many but not all media. Some strains, for example $3153 \mathrm{~A}$, were assayed at all temperatures more than ten times, and the strains presented in Table 2 were assayed at all temperatures at least three times. However, certain other strains, such as the progeny from successive platings of $\mathrm{m} 14$ and $\mathrm{m} 500$, were tested only once at 37 and $40^{\circ} \mathrm{C}$. While the results were highly reproducible from experiment to experiment with almost all media, the repeated tests with $3153 \mathrm{~A}$, for example, revealed a high degree of variability with D-arabinose and glycine. Because of the repro- 
Table 1. Carbon and nitrogen sources used in this study

\begin{tabular}{|c|c|c|}
\hline Class of compound & Representative & Source* \\
\hline Hexoses & $\begin{array}{l}\text { D-Fructose } \\
\text { D-Glucose } \\
\text { L-Sorbose }\end{array}$ & $\begin{array}{l}\text { Fruit juices and honey } \\
\text { Blood sugar, plant saps and fruits } \\
\text { Fermentation of sorbitol by Acetobacter } \\
\text { suboxydans }\end{array}$ \\
\hline Disaccharides & $\begin{array}{l}\text { D-Cellobiose } \\
\text { D-Melibiose } \\
\text { D-Trehalose }\end{array}$ & $\begin{array}{l}\text { Partial hydrolysis of cellulose } \\
\text { Partial hydrolysis of raffinose } \\
\text { Storage carbohydrate of fungi }\end{array}$ \\
\hline Trisaccharides & $\begin{array}{l}\text { D-Melezitose } \\
\text { D-Raffinose }\end{array}$ & $\begin{array}{l}\text { Exudates of various trees, including larch } \\
\text { and Douglas fir } \\
\text { Cottonseed meal and sugar beet }\end{array}$ \\
\hline Pentoses & $\begin{array}{l}\text { D-Arabinose } \\
\text { L-Arabinose } \\
\text { L-Rhamnose } \\
\text { D-Ribose } \\
\text { D-Xylose }\end{array}$ & $\begin{array}{l}\text { Prepared from glucose } \\
\text { Cherry tree gum } \\
\text { Hydrolysis of xanthorhamnin and other } \\
\text { rhamnosides } \\
\text { Hydrolysis of ribonucleic acid } \\
\text { Hydrolysis of xylans (wood sugars) }\end{array}$ \\
\hline Alcohols & $\begin{array}{l}\text { Adonitol } \\
\text { Dulcitol } \\
\text { Erythritol } \\
\text { myo-Inositol } \\
\text { Xylitol }\end{array}$ & $\begin{array}{l}\text { Adonis vernalis (family Ranunculaceae) } \\
\text { Occurs in various plants } \\
\text { Lichens, yeasts and algae } \\
\text { Widely distributed in plants, micro- } \\
\text { organisms and animals } \\
\text { Reduction of xylose }\end{array}$ \\
\hline Glycosides & $\begin{array}{l}\text { Arbutin } \\
\text { Methyl- } \alpha \text {-D-glucopyranoside }\end{array}$ & $\begin{array}{l}\text { Leaves of bear berry and other plants } \\
\text { Prepared from glucose }\end{array}$ \\
\hline Amino sugar & $N$-Acetyl-D-glucosamine & Chitin \\
\hline Amino acids & $\begin{array}{l}\text { L-Proline } \\
\text { Glycine }\end{array}$ & $\begin{array}{l}\text { Proteins such as wheat gliadin or gelatin } \\
\text { Protein such as gelatin }\end{array}$ \\
\hline Inorganic nitrogen & $\mathrm{KNO}_{3}$ & A product of nitrification in soil \\
\hline
\end{tabular}

"Merk (1983).

ducibility with $3153 \mathrm{~A}$ and other strains tested numerous times, we are confident in the overall results with strains tested only once, except for the variability on Darabinose and glycine media.

To present the results of independent experiments concisely, we have summarized certain data as follows: if there was slight variability from experiment to experiment, we have arbitrarily presented the better growth; extreme variability is presented as a range, for example, $0 / 3$ denotes the range of results with independent experiments, from no growth $(0)$ to substantial growth (3); if a given strain produced both papillae and apparently confluent growth in independent tests, the results are presented as only producing papillae, because papillae often overgrow and have the appearance of confluent growth. The formation of any papillae is simply denoted with an asterisk. Different frequencies or levels of growth of the papillae are not distinguished.

All the results are shown in Table 5, except for the following six carbon sources that were not assimilated by any strain under any of the applied temperatures and one nitrogen source that did not reveal variability: inositol, melibiose, rhamnose, cellobiose, raffinose, erythritol and $\mathrm{KNO}_{3}$. From this extensive amount of data, only some examples of mutants were chosen for a comparative presentation. The groups of mutants presented in Fig. 1 are represented in Table 2 as follows: Group A, common laboratory strains and former clinical isolates, including $3153 \mathrm{~A}$, which is also the parental strain of all the mutants presented here; Group D, spontaneous morphological mutants detected on glucose due to altered colony forms and a highly unstable spontaneous morphological mutant, m14; Groups E and $\mathrm{F}$, two $\mathrm{m} 14$ progenies, $\mathrm{m} 14-2$ and $\mathrm{m} 14-2-7$, which were derived by multiple rounds of subcloning; and Group K, positive mutants produced on non-assimilative alternative carbon sources, L-sorbose and Darabinose, after plating cells of 3153A (Rustchenko et al., 1994).

As can be seen from the comparison of the assimilation tests, the amount of growth varied with the incubation temperature, as well as with different sources. We 


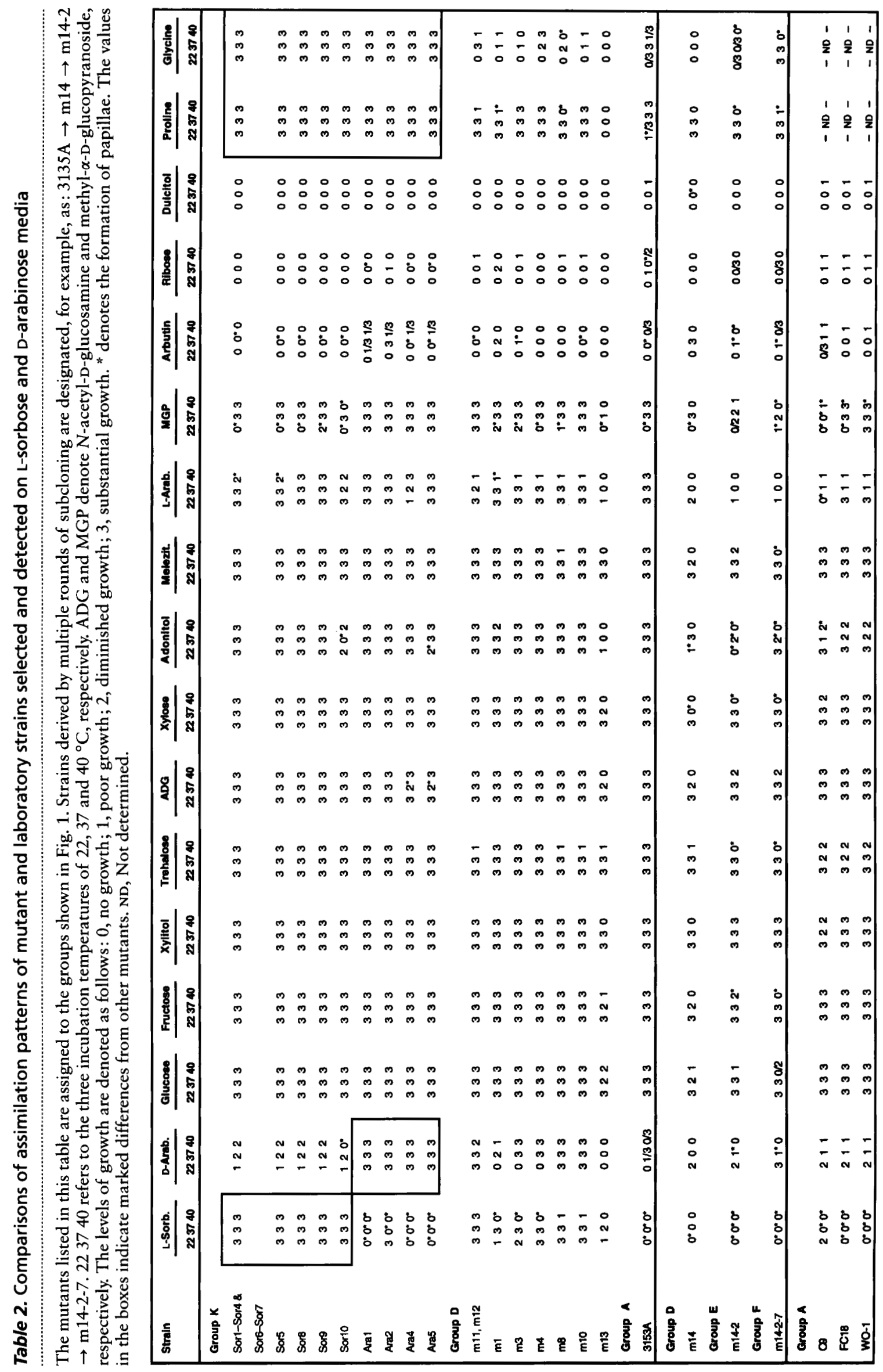



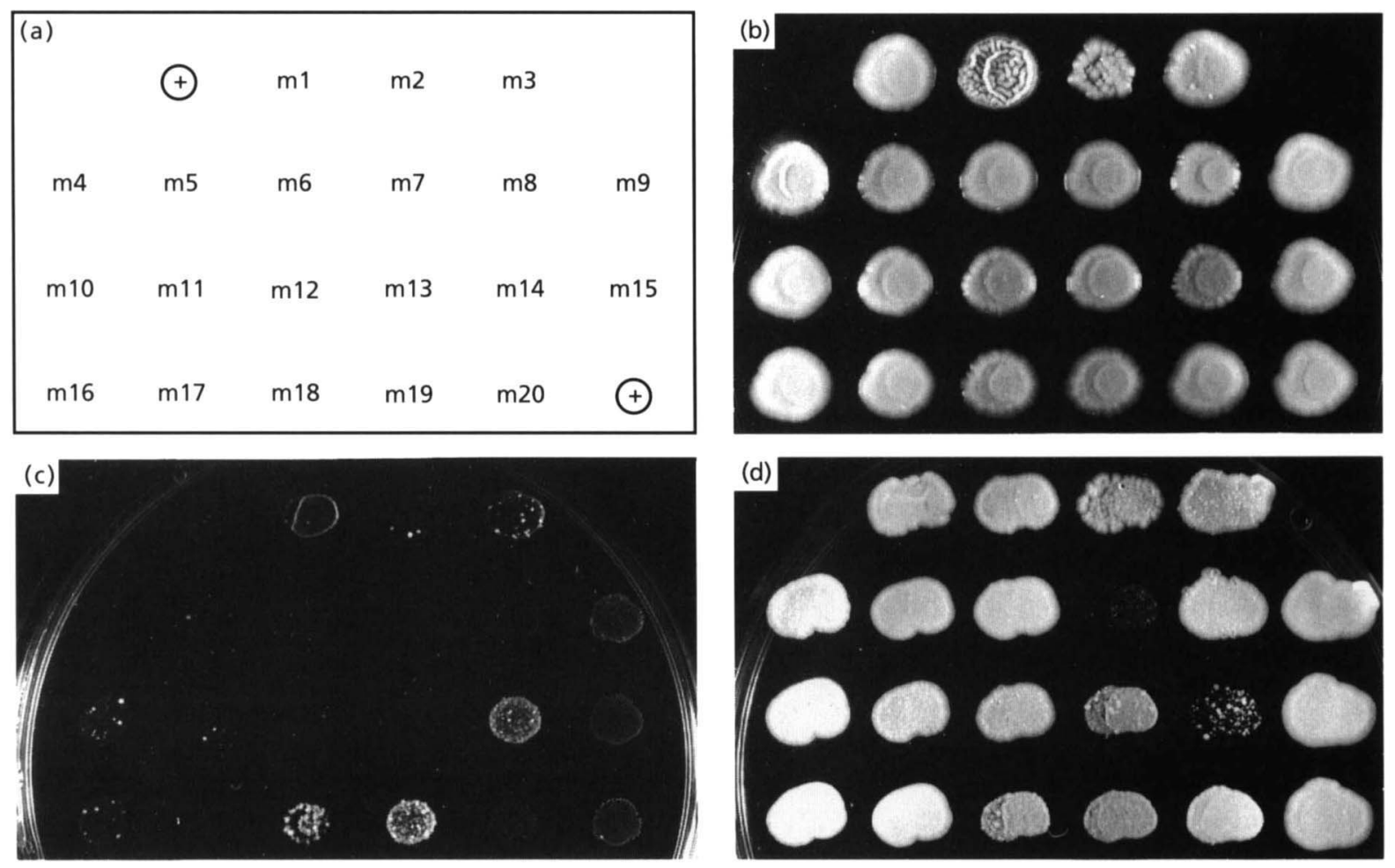

Fig. 2. Utilization patterns among morphological mutants $m 1-m 20$ and their parental strain $3153 A(+)$. (a) Schematic, (b) growth on YPD at $22^{\circ} \mathrm{C}$ for 3 weeks, (c) growth on arbutin at $37^{\circ} \mathrm{C}$ for 3 weeks and (d) growth on xylose at $37^{\circ} \mathrm{C}$ for 1 week.

assigned the responses to four levels: good growth and diminished growth (e.g. Fig. 2d, mutants m10 and m13, respectively), and poor growth and no growth (e.g. Fig. $3 c$, mutants $\mathrm{m} 14-2$ and $\mathrm{m} 14-1$, respectively). Each of the levels were assigned with a number from 3 to 0 , corresponding to good growth to no growth, respectively. Often papillae appeared instead of confluent growth (e.g. Fig. 2d, m14) or on top of various levels of growth (e.g., Fig. 3d, strain C9). They are indicated by asterisks in Tables 2 and 5. On some carbon sources, for example glucose, fructose and xylose media, high levels of growth occurred after $1 \mathrm{~d}$, whereas growth occurred only after $3 \mathrm{~d}$ on D-arabinose or melezitose media, and the level was inferior to that on glucose medium. In some cases, mutants exhibited better growth than the parental strain (3153A) in the first $3 \mathrm{~d}$, but the difference subsequently disappeared. In other cases, mutants consistently grew slightly better than 3153A. Neither of these results is presented in Tables 2 and 5.

The most important result of the assimilating tests is that all mutants showed the ability to gain or lose assimilating functions as illustrated by selected examples in Table 2, all strains except Sor1-Sor10 and Ara1-Ara5 in Table 5 and $\mathrm{m} 1-\mathrm{m} 20$ as summarized in Table 3 . Some mutants, such as $\mathrm{m} 13$ and $\mathrm{m} 14$, exhibited general heat sensitivity, being unable or almost unable to grow on any medium at $40{ }^{\circ} \mathrm{C}$ (Table 5). Others, for example $\mathrm{m} 2$ and $\mathrm{m} 18$, grew well on a few sources at $40^{\circ} \mathrm{C}$, such as methyl- $\alpha$-D-glucopyranoside or trehalose, but not on other sources. Other mutants, being largely temperaturetolerant, lost or demonstrated a greatly diminished ability to assimilate a certain source at all temperatures, for example, $\mathrm{m} 7$ on xylose and $\mathrm{D}$ - and $\mathrm{L}$-arabinose. Another example of an extreme situation was the growth on dulcitol; only three mutants, $\mathrm{m} 18, \mathrm{~m} 19$ and $\mathrm{m} 20$, assimilated this substrate and only at $40^{\circ} \mathrm{C}$. Many mutants concomitantly gained and lost assimilating functions. For example, if one considers all temperatures and enhanced growth as new functions, then $\mathrm{m} 12$ gave rise to seven acquisitions in addition to some losses. Furthermore, $\mathrm{m} 14$, being temperature-sensitive on some media, but not on others, had a total of seven losses but acquired the ability to assimilate arbutin at $37^{\circ} \mathrm{C}$. A summary of the various patterns of gains and losses of the 20 morphological mutants, $\mathrm{m} 1-\mathrm{m} 20$, are presented in Table 3 for 16 different carbon or nitrogen sources.

One important result was the change in phenotype in successive progenies. For example, mutant $\mathrm{m} 14$ did not grow on fructose at $40^{\circ} \mathrm{C}$. Its progenies $\mathrm{m} 14-2$ and $\mathrm{m} 14$ 2-7, however, acquired and lost again the function, respectively (Table 2 ). On adonitol at $22^{\circ} \mathrm{C}$, we traced the corresponding assimilating function in parental strain 3153A followed by the consequent loss and gain in its progenies. This result cannot be explained as accumulation of certain types of cells in the population because sequentially produced mutants were each de- 

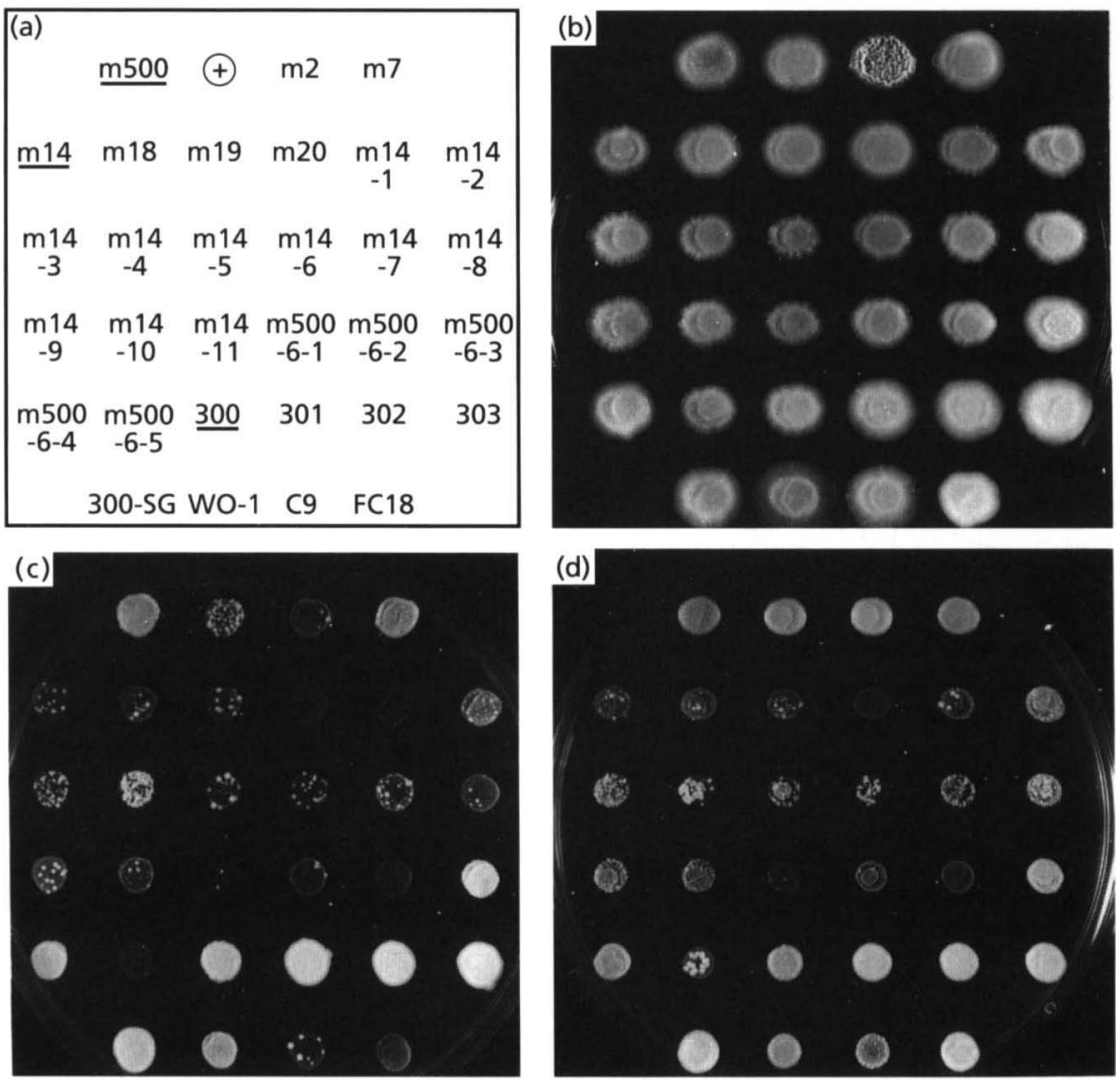

Fig. 3. Utilization patterns among different morphological mutants, their parental strain $3153 \mathrm{~A}(+)$ and three laboratory strains, WO-1, C9 and FC18. (a) Schematic, (b) growth on YPD at $22^{\circ} \mathrm{C}$ for 2 weeks, (c) growth on methyl- $\alpha$-Dglucopyranoside at $22{ }^{\circ} \mathrm{C}$ for 2 weeks and (d) growth on adonitol at $22^{\circ} \mathrm{C}$ for 2 weeks.

rived from an independent colony (Rustchenko-Bulgac, 1991). The cells derived from each of the successive platings were separated by approximately $20-25$ generations.

\section{Utilization of carbon and nitrogen sources by mutants Sor1-Sor10, Ara1, Ara2, Ara4 and Ara5, obtained under restrictive condition of growth}

The assimilation profiles of mutants obtained on nonassimilating carbon sources, L-sorbose and $\mathrm{D}$-arabinose, were analysed and partially presented by Rustchenko et al. (1994). The complete results are presented in Table 2.

\section{Utilization of carbon and nitrogen sources by common laboratory strains}

We have previously analysed the assimilation pattern of strain 3153A at three different temperatures, 22, 37 and $40{ }^{\circ} \mathrm{C}$ (Rustchenko et al., 1994). The additional strains, C9, FC18 and WO-1 were tested and compared to $3153 \mathrm{~A}$ on the same substrates at these three temperatures. All strains showed variability and temperaturedependent growth responses, similar to the results with $3153 \mathrm{~A}$ at three temperatures (Table 2).

\section{Variation in certain physiological traits as a function of storage of tester strains}

The data in Table 4 indicate that cultures of mutants stored in a refrigerator at $4{ }^{\circ} \mathrm{C}$ may vary from the parental strain. We have reported previously that the highly variable nature of $C$. albicans would be manifested in cultures not adequately preserved (RustchenkoBulgac, 1991). Thus, storage at $-70^{\circ} \mathrm{C}$ is recommended to prevent the erratic appearance of phenotypic variations.

\section{DISCUSSION}

The chromosomal variability of C. albicans is well documented for natural isolates (Asakura et al., 1991; Merz et al., 1988) and laboratory strains (RustchenkoBulgac, 1991; Thrash-Bingham \& Gorman, 1992), as well as variants derived spontaneously from the same strain (Rustchenko-Bulgac, 1991; Rustchenko-Bulgac \& Howard, 1993; Suzuki et al., 1989; M. J. McEachern, unpublished results). The analyses of electrophoretic karyotypes revealed that the patterns of chromosomal variability among naturally occurring strains are strikingly similar to the patterns among spontaneous 
Table 3. Summary of the various patterns of the growth of spontaneous morphological mutants $\mathrm{m} 1-\mathrm{m} 20$ on 16 different sources of carbon and nitrogen

Substrates included were glucose, fructose, sorbose, trehalose, melezitose, L- and D-arabinose, ribose, xylose, adonitol, arbutin, methyl- $\alpha$-D-glucopyranoside, $N$-acetyl-D-glucosamine, xylitol, proline and glycine. The designations used are: Gain, acquisition or increased ability to utilize one or more substrates; Loss, loss or decreased ability to utilize one or more substrates; Both, gain and loss of ability to utilize substrates. Production of papillae is not presented in this table.

\begin{tabular}{|llll|}
\hline Mutants & $22^{\circ} \mathrm{C}$ & $\mathbf{3 7}{ }^{\circ} \mathrm{C}$ & $\mathbf{4 0}{ }^{\circ} \mathrm{C}$ \\
\hline $\mathrm{m} 1, \mathrm{~m} 16, \mathrm{~m} 17$ & Gain & Gain & Loss \\
$\mathrm{m} 2$ & Gain & Both & Loss \\
$\mathrm{m} 3, \mathrm{~m} 8, \mathrm{~m} 10, \mathrm{~m} 15$ & Gain & Gain & Both \\
$\mathrm{m} 4, \mathrm{~m} 9$ & Gain & Gain & Gain \\
$\mathrm{m} 5$ & Loss & Both & Both \\
$\mathrm{m} 6$ & Loss & Loss & Both \\
$\mathrm{m} 7$ & Both & Loss & Loss \\
$\mathrm{m} 11, \mathrm{~m} 12$ & Both & Both & Both \\
$\mathrm{m} 13$ & Loss & Both* & Loss* \\
$\mathrm{m} 14$ & Both & Both* & Loss \\
$\mathrm{m} 18, \mathrm{~m} 19, \mathrm{~m} 20$ & Both & Both & Both* \\
\hline
\end{tabular}

* The number of carbon sources was equal to or larger than half of the total.

mutants (Rustchenko-Bulgac, 1991). The observations of the chromosomal alterations of the highly unstable variants derived from strain $3153 \mathrm{~A}$ revealed that a single variant can give rise to a substantial level of karyotypic variability within a population (Rustchenko-Bulgac, 1991). A relatively high level of spontaneous karyotypic diversity in a population explains natural chromosomal variability. We also suggested that spontaneous chromosomal aberrations are a means for generating genetic variability in an organism that lacks mating and the meiotic process (Rustchenko-Bulgac et al., 1990).

To elucidate chromosomal alterations and to identify the related advantageous phenotypes, we have further investigated a collection of spontaneously derived morphological mutants, which were isolated from strain $3153 \mathrm{~A}$ as having altered colony morphologies (Rustchenko-Bulgac, 1991). A total of 46 morphological mutants were examined previously for their electrophoretic karyotypes and all of them revealed a broad range of single and multiple chromosomal changes (Rustchenko-Bulgac et al., 1990; Rustchenko-Bulgac, 1991; Rustchenko-Bulgac \& Howard, 1993). This result established a correlation between alterations in colony appearances, which has been the subject of numerous reports for several decades (for review, see Odds, 1988), and chromosomal constitutions. We assume that the remaining 60 morphological mutants out of the 106 discussed in this paper also have altered chromosomes. The most important fact about the 106 morphological mutants presented here is that each mutant has an individual assimilation profile on a number of carbon and nitrogen sources (Table 5). This is in agreement with another important fact, that each mutant possesses a uniquely altered electrophoretic karyotype (Rustchenko-Bulgac et al., 1990; Rustchenko-Bulgac, 1991; Rustchenko-Bulgac \& Howard, 1993). In a manner similar to the parental strain 3153A (Rustchenko et al., 1994), the assimilations are temperature-dependent. Most importantly, the differences in assimilation profiles include both acquisitions and losses of functions. As presented in Table 3 for the mutants $m 1-\mathrm{m} 20$, some profiles include multiple changes of more than a half of the traits (see Results for additional information). This

Table 4. Comparison of certain attributes of some arbitrarily chosen morphological mutants stored under different conditions

The tests were selected from the scheme of Odds \& Abbott (1980) for typing isolates of C. albicans. Growth was recorded as: + , good growth; \pm , diminished growth; 0 , no growth. Other levels or forms of growth are not presented. Stored indicates stored on slants of GPA agar in a refrigerator for 6 months; fresh indicates fresh inoculum recovered from glycerol suspension stored at $-70{ }^{\circ} \mathrm{C}$ and tested after first subcloning on GPA.

\begin{tabular}{|lcccc|}
\hline Strain & $\begin{array}{c}\text { Tolerance to } \\
\text { pH 1.55 }\end{array}$ & $\begin{array}{c}\text { Urea } \\
\text { assimilation }\end{array}$ & $\begin{array}{c}\text { Sorbose } \\
\text { assimilation }\end{array}$ & $\begin{array}{c}\text { Tolerance to } \\
\text { salt }\end{array}$ \\
\hline $3153 \mathrm{~A}$ & + & + & + & + \\
$\mathrm{m}$ 14 stored & \pm & + & + & + \\
$\mathrm{m}$ 14 fresh & + & 0 & 0 & \pm \\
$\mathrm{m}$ 2 stored & + & 0 & + & + \\
$\mathrm{m}$ 2 fresh & + & + & + & + \\
$\mathrm{m}$ 6 stored & + & + & \pm & + \\
$\mathrm{m}$ 6 fresh & + & + & 0 & + \\
$\mathrm{m}$ 7 stored & + & 0 & \pm & + \\
$\mathrm{m}$ 7 fresh & + & 0 & + \\
\hline
\end{tabular}


large number of different phenotypes is consistent with a large repertoire of single and multiple chromosomal aberrations in these mutants, which are represented at least by duplications, deletions and translocations (Rustchenko-Bulgac et al., 1990; Rustchenko-Bulgac, 1991 ; Rustchenko-Bulgac \& Howard 1993). As obviously seen from our results, spontaneous mutants have a high degree of variability of assimilating functions. In addition, the temperature dependency adds to the complexity. Instances of apparent reversibility are noted, which can be special cases of just variability. Furthermore, in a few cases of phenotypic reversibility, we have not observed 'reversion' of altered karyotypes. For example, the parental strain 3153A grew well on xylose medium at $37^{\circ} \mathrm{C}$, the m14 mutant did not grow at all, and all but one of the m14 derivatives grew well on this medium (Table 5). In contrast, the karyotypes of $\mathrm{m} 14$ revealed multiple chromosomal duplications, whereas the karyotypes of the $\mathrm{m} 14$ derivatives differed from each other and from $\mathrm{m} 14$ by having different combinations of duplicated chromosomes as well as chromosomes with changed lengths (RustchenkoBulgac, 1991). Furthermore, the parental strain 3153A did not grow on D-arabinose medium at $22^{\circ} \mathrm{C}, \mathrm{m} 14$ grew on this medium, whereas the two derivatives, m143 and m14-7 did not (Table 5). On the other hand, the m14-3 and m14-7 strains had multiple chromosomal changes and the karyotypes differed from $\mathrm{m} 14$ and the 3153A parental strain, as well as from each other (Rustchenko-Bulgac, 1991). Thus, the patterns of assimilations are complex, and bear no simple relationships with spontaneous chromosomal alterations. The mechanism of phenotypic variability and its possible causal relationship to chromosomal alteration has yet to be elucidated.

Spontaneous morphological mutants of C. albicans with altered assimilation patterns have been reported previously, most notably by Brown-Thomsen (1968). In a review, Soll (1990) briefly reported that changes of assimilation patterns were correlated with strains undergoing white-opaque transition. The lack of experimental detail makes it difficult to evaluate his results. Furthermore, as discussed in the Introduction, the white-opaque transitions are distinct from the alterations of colony morphology with the accompanying electrokaryotypic changes.

The natural isolates are also known to have variable assimilation profiles (API 20C Clinical Yeast System, API Laboratory Products Ltd, 1990; see also Rustchenko et al., 1994). As shown in Table 2, the differences are comparable with the variability among morphological mutants. This is in agreement with our hypothesis, that chromosomal aberrations within the same population are responsible for the karyotypic and phenotypic variability among natural strains.

Earlier in our analysis of the high chromosomal instability of mutants $\mathrm{m} 500$ and $\mathrm{m} 14$, we concluded that such instability is a means to achieve a wide range of phenotypes within a population (Rustchenko-Bulgac, 1991). The various combinations of assimilative func- tions, observed in this study, associated with the same cascade of spontaneous descendants of $\mathrm{m} 500$ and $\mathrm{m} 14$ (Fig. 1), are consistent with our earlier conclusion. Because each successive descendent was independently derived as an altered colony mutant (RustchenkoBulgac, 1991), the gains and losses constantly occurred de novo, thus permanently providing the organism with multiple new combinations of assimilative functions as can be seen in Table 5 or in Table 2 for a few examples. The complex picture of functional losses and gains of nutritional factors in C. albicans is highly reminiscent of well studied cryptic genes for alternative carbon sources in Escherichia coli (Reynolds et al., 1981; Hall, 1982; Hall et al., 1986).

We wish to emphasize that we previously analysed a number of phenotypes, other than assimilative functions, that were associated with morphological mutants. Some of them, such as colony and cell morphology, although associated with altered electrokaryotypes, did not appear to be critical for survival of the organism. Furthermore, these traits may be determined by many genes. Others, such as the inability to form germ-tubes or chlamydospores, as well as diminution of adherence and pathogenicity, were sporadically observed, and appeared to arise by destruction of functions (Rustchenko-Bulgac \& Howard, 1993; C. Haidaris, unpublished results; E. DiDomenico, unpublished results). Because each morphological mutant exhibits multiple changes in its assimilation abilities, which are important physiological functions, and changes in a limited spectrum of other mutations as mentioned above, though not in many other possible mutations, such as those causing auxotrophy (Rustchenko-Bulgac \& Howard, 1993), we believe that these high rates of mutagenesis are not truly random and are restricted to specific groups of genes.

In our previous study (Rustchenko et al., 1994), we observed a correlation between specific chromosomal aberrations and the expression of specific cryptic genes required for assimilative functions. The mutants analysed included ten sorbose-positive and 15 arabinosepositive mutants that were obtained by plating cells of $3153 \mathrm{~A}$ on media containing non-assimilative sources of carbon, L-sorbose and D-arabinose, respectively. The sorbose- and arabinose-positive mutants appeared at high frequencies, in the order of $10^{-3}$, after $4 \mathrm{~d}$ of delay and continued to arise during at least 2 weeks of incubation in an accumulative fashion. When repeatedly plated on L-sorbose and D-arabinose media, all mutants produced colonies after $2 \mathrm{~d}$ growth, without a lag period. Such traits are indicative of 'adaptive' mutagenesis as observed in E. coli (Cairns et al., 1988) and some other organisms (Steele \& Jinks-Robertson, 1992; Nochur et al., 1990; Malavasic \& Cihlar, 1992). It is important that examples of mutations leading to the utilization of alternative carbon sources were uncovered in some of these studies. Each positive phenotype was associated with a different and specific chromosomal aberration, a result which is reminiscent of adaptive mutagenesis with the $B g l$ system of $E$. coli, in which the 


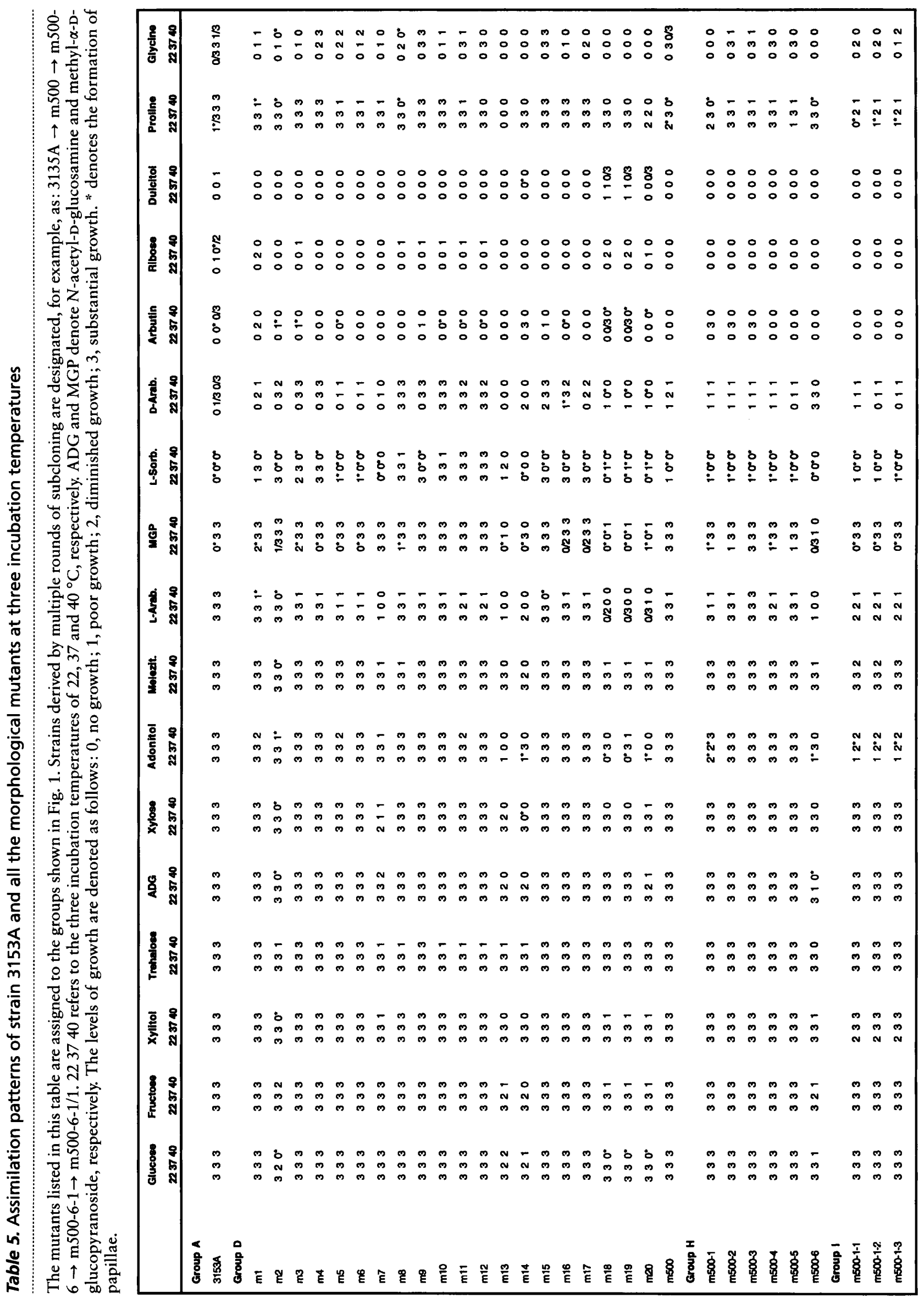




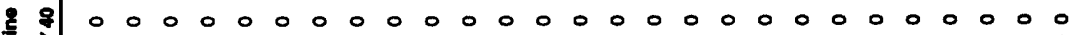
包

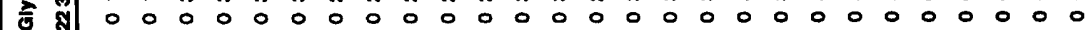

- : 000000000000 000000000000000

8 우 - - - - - - - - - - - - - - - - - - - - - 000000

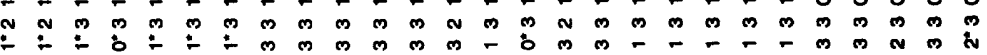

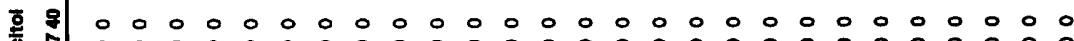
月ิ

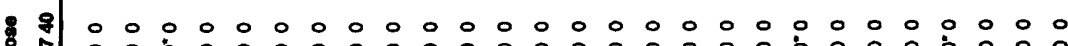
華

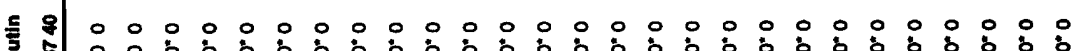
売

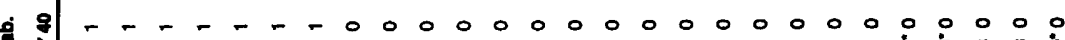
15

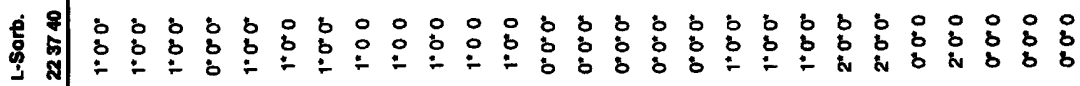

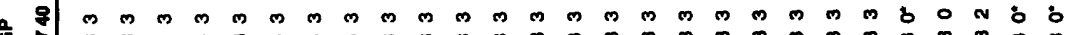

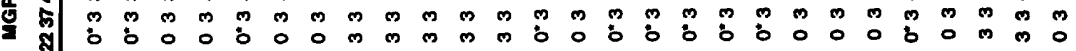

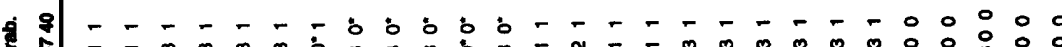

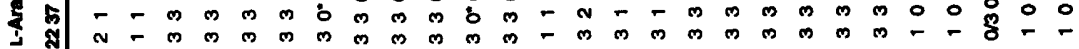

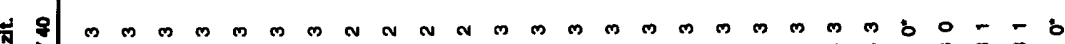

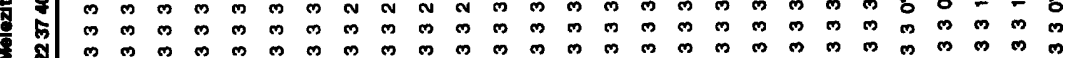

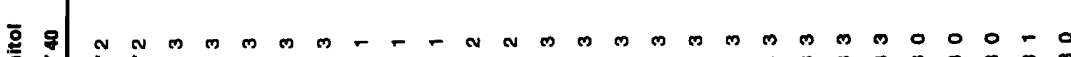

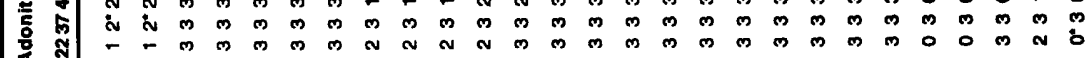

8 I

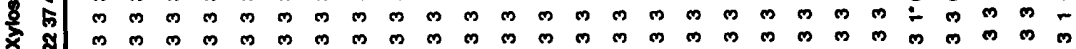

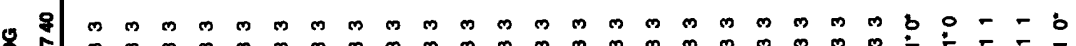

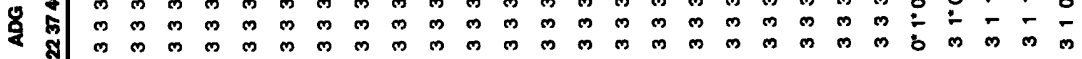

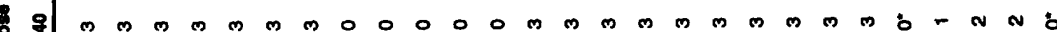

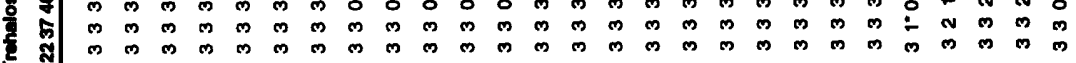

- 8 - 5 D

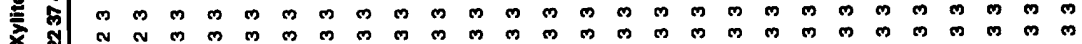

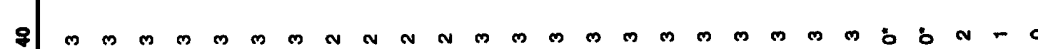

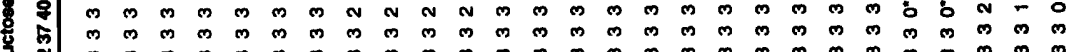
趈

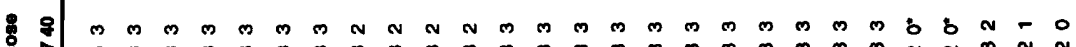

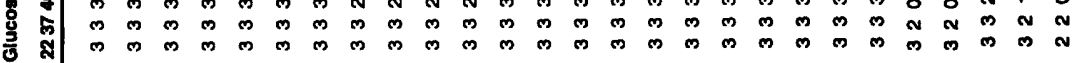
0 -

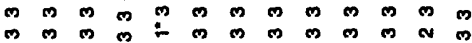

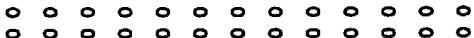

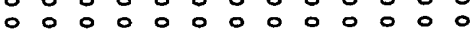

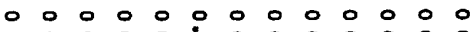
$\begin{array}{lllllllllllll}0 & 0 & 0 & 0 & 0 & 0 & 0 & 0 & 0 & 0 & 0 & 0 & 0 \\ 0 & 0 & 0 & 0 & 0 & 0 & 0 & 0 & 0 & 0 & 0 & 0 & 0\end{array}$

- 000000000000

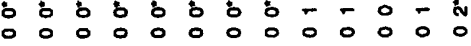

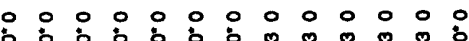

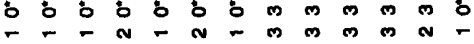

o

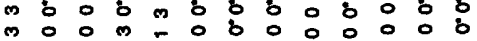

- b j b o - o n n n n -0

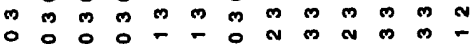

$\begin{array}{llllllllllllll}0 & 0 & 0 & 0 & 0 & 0 & 0 & 0 & 0 & 0 & 0 & 0 & 0\end{array}$

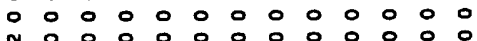

0 : 000 : 0 : $-0.0 \%$ $\begin{array}{lllllllllllll}0 & 0 & 0 & 0 & 0 & \infty & 0 & 0 & \infty & \infty & \infty & 0 & 0 \\ 0 & 0 & 0 & 0 & 0 & 0 & 0 & 0 & 0 & 0 & 0 & 0 & 0\end{array}$

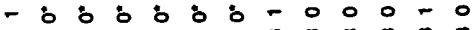
m

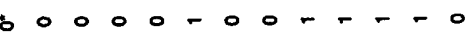

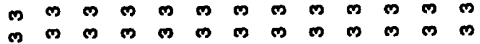

- $\begin{array}{lllllllllllll}1 & 0 & 0 & 0 & 0 & 0 & 0 & 0 & \infty & 0 & 0 & 0 & - \\ 0 & 0 & 0 & 0 & 0 & 0 & 0 & 0 & 0 & 0 & 0 & 0 & 0\end{array}$

r

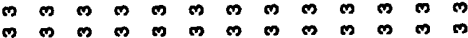

- 0 b 0 b -

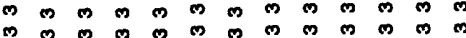

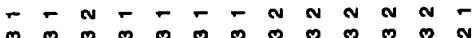

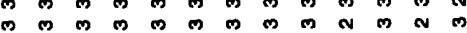

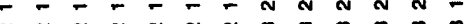

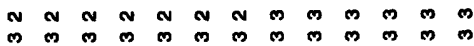

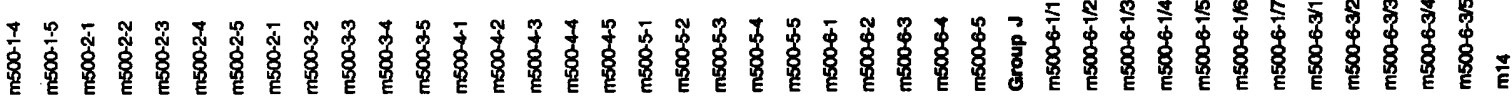




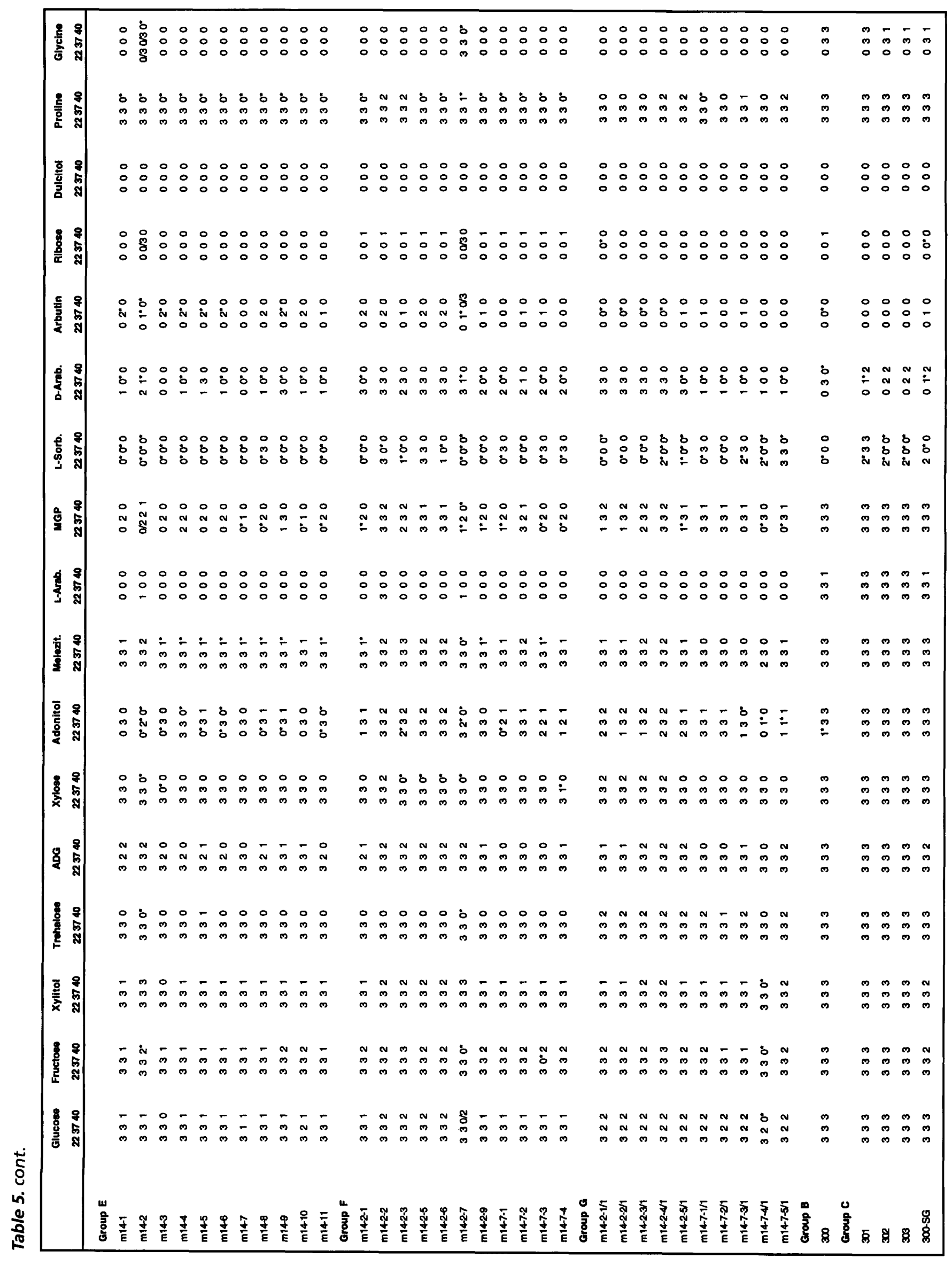


specific mutations cause the expression of cryptic genes (Reynolds et al., 1981). Furthermore, the positive mutants uncovered among the morphological mutants in this investigation differed from the positive mutants recovered under restrictive growth on L-sorbose and Darabinose media as summarized in Table 2 . The morphological mutants were compared to all ten sorbose-positive mutants, Sor1-Sor10, and four arabinosepositive mutants, Ara1, Ara2, Ara4 and Ara5, which were not temperature-sensitive (for details, see Rustchenko et al., 1994). However, only two morphological mutants, $\mathrm{m} 11$ and $\mathrm{m} 12$, exhibited extensive growth on sorbose medium, comparable to the Sor1-Sor10 mutants, whereas six other morphological mutants grew only partially on L-sorbose medium, thus limiting the comparison. Also, it was not possible to separately compare the mutants which gained the ability to assimilate D-arabinose, because the sorbose- and arabinose-positive phenotypes concomitantly occurred together in many of the morphological mutants.

As summarized in Table 2, mutants obtained on restrictive media generally exhibited uniform properties. For example, Sor1-Sor 10 did not show altered responses on $\mathrm{D}$-arabinose, arbutin, ribose, proline or glycine media, and were in this respect similar to the parental strain $3153 \mathrm{~A}$. Only one mutant, Sor10, was somewhat different, and the others, Sor1-Sor9, were completely or almost completely identical. Specifically, all positive mutants obtained under restrictive conditions grew well on both alternative nitrogen sources, proline and glycine, whereas the positive mutants uncovered among morphological mutants were highly variable on these media and differed from the parental strain. Furthermore, the positive mutants obtained under restrictive conditions exhibited specific chromosomal aberrations: chromosome III for sorbose-positive mutants and chromosome II or VI for arabinose-positive mutants (Rustchenko et al., 1994). In contrast, morphological mutants contained many simultaneous phenotypic changes. The chromosomal aberrations were diverse and multiple, without any obvious chromosomal pattern. For example, sorbose-positive mutants uncovered from among the morphological mutants were not associated with a change in chromosome III, as were the Sor1-Sor10 mutants. Of eight sorbose-positive morphological mutants presented in Table 2 , only $\mathrm{m} 1$ has a change in chromosome III, similar to the specific aberrations. Furthermore, the acquisition of assimilation of L-sorbose was not found in any of the 11 morphological mutants, including $\mathrm{m} 500$ and their derivatives, known to have changes in chromosome III, similar to the specific changes associated with the positive mutants obtained on L-sorbose medium (for a description of the karyotypes, see Rustchenko-Bulgac, 1991). The different phenotypic and karyotypic patterns observed with the positive mutants obtained under restrictive conditions, and those uncovered from among morphological mutants suggest that two different mechanisms may be responsible for their formation.

A broad spectrum of multiple chromosomal rearrange- ments in spontaneous morphological mutants leading to changes in gene expression suggests the involvement of mobile elements similar to, for example, Ty elements in Saccharomyces cerevisiae (Roeder \& Fink, 1980). Interestingly, the frequencies of chromosomal aberrations increase almost tenfold after incubation at low temperature (Rustchenko-Bulgac et al., 1990), a property previously reported for Ty elements (Paquin \& Williamson, 1984). The expression of physiologically important features chosen by us from the biotyping method of Odds \& Abbott (1980) changed consistently after storage at low temperature as well. A few examples of this sort of variation are presented in Table 4. Such variability could account for the reported inter-laboratory variation which has compromised the usefulness of classification procedures (Odds et al., 1989).

As Borst \& Greaves (1987) pointed out, the reaction of a microbe to the major changes in nutrient supply is expected to be of two kinds, a pre-adaptation of a fraction of the population through DNA rearrangements, as well as adaptation after an actual change. The latter, possibly, is more fruitful, because starvation is not immediately lethal, and new food supplies are not a temporary opportunity. We suggest that two phenomena related to the formation of similar but not identical phenotypes, positive mutants produced spontaneously during growth in glucose medium and positive mutants produced on a restrictive medium as a response to the environment, appear to correspond to two different mutagenic processes. Both mechanisms responsible for the formation of positive mutants should be revealed from the analysis of cloned genes. Such studies are in progress.

Thus, C. albicans has developed a complicated but effective means for controlling gene expression to survive in specific and variable niches, including the mucous lining of the gastrointestinal tract with its changing flows of food with microbial competition, and changes of mammalian host and prevalent diet.

\section{ACKNOWLEDGEMENTS}

The work was supported by US Public Health Service Grants AI29433 (F.S.) and AI22963 (D.H.H) from the National Institutes of Health. We thank $H$. Kolbel for technical assistance.

\section{REFERENCES}

Asakura, K., Iwaguchi, S.-I., Homma, M., Sukai, T., Higashide, K. \& Tanaka, K. (1991). Electrophoretic karyotypes of clinically isolated yeasts of Candida albicans and C. glabrata. J Gen Microbiol 137, 2531-2538.

Borst, P. \& Greaves, D. R. (1987). Programmed gene rearrangements altering gene expression. Science 235, 658-667.

Brown-Thomsen, J. (1968). Variability in Candida albicans. Hereditas 60, 355-398.

Cairns, J., Overbaugh, J. \& Miller, S. (1988). The origin of mutants. Nature 335, 142-145.

Hall, B. G. (1982). Chromosomal mutation for citrate utilization by Escherichia coli K-12. J Bacteriol 151, 269-273. 
Hall, B. G., Betts, P. W. \& Kricker, M. (1986). Maintenance of the cellobiose utilization genes of Escherichia coli in a cryptic state. Mol Biol Evol 3, 389-402.

Howard, D. H., Zeuthen, M. L. \& Dabrowa, N. (1986). Phenotypic characteristics of a slow-growing, nongerminating variant of Candida albicans. J Gen Microbiol 132, 2359-2366.

Lee, K. L., Buckley, H. R. \& Campbell, C. C. (1975). An amino acid liquid synthetic medium for the development of mycelial and yeast forms of Candida albicans. Sabouraudia 13, 148-153.

Mackinnon, J. E. (1940). Dissociation in Candida albicans. JInfect Dis 66, 59-77.

Malavasic, M. J. \& Cihlar, R. L. (1992). Growth response of several Candida albicans strains to inhibitory concentrations of heavy metals. J Med Vet Mycol 30, 421-432.

Meitner, S. W., Bowen, W. H. \& Haidaris, S. G. (1990). Oral and esophogeal Candida albicans infection in hyposalivatory rats. Infect Immun 58, 2228-2236.

Merk (1983). Merk Index, 10th edn. Rahway, NJ: Merk and Co. Inc.

Merz, W. G., Connelly, C. \& Heiter, P. (1988). Variation of electrophoretic karyotypes among clinical isolates of Candida albicans. J Clin Microbiol 26, 842-845.

Negroni, P. (1935). Variacion hacia el tipo R de Mycotorula albicans. Rev Soc Argent Bio 11, 449-453.

Nochur, S. V., Roberts, M. F. \& Demain, A. L. (1990). Mutation of Clostridium thermocellum in the presence of certain carbon sources. FEMS Microbiol Lett 71, 199-204.

Odds, F. C. (1988). Candida and Candidosis. London: Balliere Tindall.

Odds, F. C. \& Abbott, A. B. (1980). A simple system for the presumptive identification of Candida albicans and differentiation of strains within the species. Sabouraudia 18, 301-318.

Odds, F. C., Auger, P., Krogh, P., Neely, A. N. \& Segal, E. (1989). Biotyping of Candida albicans: results of an international collaborative study. J Clin Microbiol 27, 1506-1509.

Paquin, C. E. \& Williamson, V. M. (1984). Temperature effects on the rate of Ty transposition. Science 226, 53-54.

Pomés, R., Gil, C. \& Nombela, C. (1985). Genetic analysis of Candida albicans morphological mutants. J Gen Microbiol 131, 2107-2113.

Reynolds, A. E., Felton, J. \& Wright, A. (1981). Insertion of DNA activates the cryptic $b g l$ operon in E. coli K12. Nature 293, 625-629.

Rikkerink, E. H. A., Magee, B. B. \& Magee, P. T. (1988). Opaquewhite transition: a programmed morphological transition in Candida albicans. J Bacteriol 170, 895-899.

Roeder, G. S. \& Fink, G. (1980). DNA rearrangements associated with a transposable element in yeast. Cell 21, 239-249.
Rustchenko, E. P., Curran, T. \& Sherman, F. (1993). Variations in the number of ribosomal DNA cistrons in normal and mutant strains of Candida albicans and in normal strains of Saccharomyces cerevisiae. J Bacteriol 175, 7189-7199.

Rustchenko, E. P., Howard, D. H. \& Sherman, F. (1994). Chromosomal alterations of Candida albicans are associated with the gain and loss of assimilating functions. J Bacteriol 176, 3231-3241.

Rustchenko-Bulgac, E. P. (1991). Variation of Candida albicans electrophoretic karyotypes. J Bacteriol 173, 6586-6596.

Rustchenko-Bulgac, E. P. \& Howard, D. H. (1993). Multiple chromosomal and phenotypic changes in spontaneous mutants of Candida albicans. J Gen Microbiol 139, 1195-1207.

Rustchenko-Bulgac, E. P., Sherman, F. \& Hicks, J. B. (1990). Chromosomal rearrangements associated with morphological mutants provide a means for genetic variation of Candida albicans. J Bacteriol 172, 1276-1283.

Sherman, F., Fink, G. R. \& Hicks, J. B. (1986). Laboratory Course Manual for Yeast Genetics and Molecular Biology. Cold Spring Harbor, NY: Cold Spring Harbor Laboratory.

Slutsky, B., Buffo, J. \& Soll, D. R. (1985). High frequency switching of colony morphology in Candida albicans. Science 230, 666-669.

Slutsky, B., Staebell, M., Anderson, J., Risen, L., Pfaller, M. \& Soll, D. R. (1987). 'White-opaque transition': a second high-frequency switching system in Candida albicans. J Bacteriol 169, 189-197.

Soll, D. R. (1990). Dimorphism and high frequency switching in Candida albicans. In The Genetics of Candida albicans, pp. 147-176. Edited by D. Kirsch, R. Kelly \& M. B. Kurtz. Boca Raton, FL: CRC Press.

Steele, D. F. \& Jinks-Robertson, S. (1992). An examination of adaptive reversion in Saccharomyces cerevisiae. Genetics 132, 9-21.

Suzuki, T., Kobayashi, I., Kanbe, T. \& Tanaka, K. (1989). High frequency variation of colony morphology and chromosome reorganization in the pathogenic yeast Candida albicans. J Gen Microbiol 135, 425-434.

Suzuki, T., Miyamae, Y. \& Ishida, I. (1991). Variation of colony morphology and chromosomal rearrangement in Candida tropicalis. J Gen Microbiol 137, 161-167.

Thrash-Bingham, C. \& Gorman, J. (1992). DNA translocations contribute to chromosome length polymorphisms in Candida albicans. Curr Genet 22, 93-100.

Vasilas, A., Molina, L., Hoffman, M. \& Haidaris, C. G. (1992). The influence of morphological variation on Candida albicans adhesion to denture acrylic in vitro. Arch Oral Biol 37, 612-622.

Vogel, R. A. \& Sponcler, R. S. (1970). The study and significance of colony dissociation in Candida albicans. Sabouraudia 7, 273-278.

Received 4 July 1996; revised 3 January 1997; accepted 13 January 1997. 